\title{
Influence of manganese content and finish rolling temperature on the martensitic transformation of ultrahigh-strength strip steels
}

\author{
$\underline{\text { Antti Kaijalainen }}{ }^{1}$, Mahesh Somani ${ }^{1}$, Mikko Hemmilä ${ }^{2}$, Tommi Liimatainen ${ }^{2}$, David A. Porter ${ }^{1}$, Jukka Kömi ${ }^{1}$ \\ ${ }^{1}$ Materials and Production Engineering, University of Oulu, Finland \\ ${ }^{2}$ SSAB Europe Oy, Raahe, Finland
}

\begin{abstract}
The effects of manganese content and finish rolling temperature (FRT) on the transformed microstructures and properties of two low-alloyed thermomechanically rolled and direct-quenched (TM-DQ) steels were investigated. The materials were characterized in respect of microstructures and tensile properties. In addition, microhardness measurements were made both at the surface and centerline of the hot-rolled strips to help characterize the phase constituents. Detailed microstructural features were further revealed by laser scanning confocal microscopy (LSCM) and field emission scanning electron microscopy combined with electron backscatter diffraction (FESEM-EBSD). It was apparent that a decrease in the temperature of controlled rolling, i.e., the finish rolling temperature (FRT), resulted in reduced martensite fractions at the surface, as a consequence of strain-induced fine ferrite formation. The centerline of the strip, however, comprised essentially martensite and upper bainite. In contrast, high FRT and higher manganese content resulted in essentially a fully martensitic microstructure due to enhanced hardenability. The paper presents a detailed account of the hot rolling and hardenability aspects of TM-DQ ultra-high-strength strip steels and corresponding microstructures and properties.
\end{abstract}

Keywords: direct quenching, hardenability, microstructure, prior austenite morphology, ultrahigh-strength

\section{INTRODUCTION}

In recent years, low-carbon high-strength steels with yield strength in the range 800 to $1100 \mathrm{MPa}$ produced using the TM-DQ processing route have become interesting materials for structural applications, because these steels can exhibit good combinations of mechanical properties and weldability [1-3]. The microstructures of these steels often comprise bainite and/or auto-tempered martensite $[1,4,5]$. In the case of TM-DQ strip steels, cold bending is the most important method of forming in applications such as containers and crane booms. The bendability improves remarkably when the steel hardness just below the surface is marginally lower than in the bulk owing to the presence of a mixture of ferritic and granular bainitic microstructure near the surface, in contrast to the generally bainitic and/or martensitic microstructure in the bulk of the steel, as the condition for the onset of strain localization and shear band formation is thereby significantly averted [6]. It has also been shown that the near-surface properties, i.e., the properties of the steel down to a depth of approximately $5 \%$ of the total sheet thickness, govern the bendability [6].

Hence, it is important to ascertain the factors and underlying mechanisms leading to the formation of a relatively soft microstructure at the surface in order to impart the best possible combinations of yield strength, toughness, ductility and bendability to these high-strength steels. The phase transformation characteristics have been found to be dependent not only on the chemical composition [7-10], but also on the extent of austenite pancaking and FRT [7,11]. Specific TM processing steps were developed in order to obtain a relatively hard core with a bainite/martensite microstructure and a softer ferrite/granular bainite surface layer resulting from controlled strain-induced transformation.

The main aim of this study is to establish the influence of FRT and manganese content on the hardenability characteristics and subsequent phase transformation characteristics, microstructural features and resultant properties. In particular, the circumstances leading to the desired manifestation of a relatively soft surface microstructure have been established, in accord with some pilot scale processed and direct-quenched highstrength steel strips recently processed at the authors' laboratory [6]. This paper presents a comprehensive summary of the results with special emphasis on the hardenability and phase transformation aspects verified 
through CCT simulations to understand the microstructure development and related hardness as a function of austenite state and cooling rate.

\section{MATERIALS AND EXPERIMENTAL PROCEDURES}

The experimental materials were produced as $210-\mathrm{mm}$-thick continuously cast slabs that were reheated to $1250{ }^{\circ} \mathrm{C}$ and then hot rolled at pilot scale under thermomechanical control to final strip thickness (t) of 8 $\mathrm{mm}$, followed by direct quenching to room temperature at a rate of $\sim 50-70{ }^{\circ} \mathrm{C} / \mathrm{s}$. The finish rolling temperature (FRT) was varied in the range $800-920{ }^{\circ} \mathrm{C}$. Manganese was varied between two levels and the chemical compositions of the two steels are given in Table I. Also included in the table are the nonrecrystallization temperatures $\left(\mathrm{T}_{\mathrm{NR}}\right)$ of the two compositions calculated using the formula given in Ref. [12], as well as the martensite and bainite start temperatures $\left(\mathrm{M}_{\mathrm{S}}\right.$ and $\left.\mathrm{B}_{\mathrm{S}}\right)$ determined using JMatPro ${ }^{\circledR}$ simulation software (Sente Software Ltd.). The software was also used for plotting the CCT diagrams of the two steels. The material identification codes were so applied in order to describe the chemical composition of the steel (Low Mn or High Mn) and the finish rolling temperature (920-800 ${ }^{\circ} \mathrm{C}$ ), e.g., Low Mn-800, etc.

Table I. Chemical compositions (in wt.\%) of the investigated steels along with their $T_{N R}, M_{S}$ and $B_{S}$ temperatures.

\begin{tabular}{lccccccccccc}
\hline Steel & $\mathrm{C}$ & $\mathrm{Si}$ & $\mathrm{Mn}$ & $\mathrm{Cr}$ & $\mathrm{Ti}$ & $\mathrm{B}$ & $\mathrm{Nb}$ & $\mathrm{V}$ & $\begin{array}{c}\mathrm{T}_{\mathrm{NR}} \\
\left({ }^{\circ} \mathrm{C}\right)\end{array}$ & $\begin{array}{c}\mathrm{M}_{\mathrm{S}} \\
\left({ }^{\circ} \mathrm{C}\right)\end{array}$ & $\begin{array}{c}\mathrm{B}_{\mathrm{S}} \\
\left({ }^{\circ} \mathrm{C}\right)\end{array}$ \\
\hline Low Mn & $\mathbf{0 . 0 7}$ & 0.2 & $\mathbf{1 . 4}$ & 1.0 & 0.02 & 0.0013 & 0.04 & 0.011 & 987 & 439 & 602 \\
High Mn & $\mathbf{0 . 0 8}$ & 0.2 & $\mathbf{1 . 8}$ & 1.0 & 0.02 & 0.0015 & 0.04 & 0.017 & 997 & 419 & 586 \\
\hline
\end{tabular}

A general characterization of the transformation microstructures was performed with a laser scanning confocal microscope (LSCM VK-X200, Keyence Ltd.) and a FESEM (Ultra plus, Zeiss) microscope on specimens etched with nital or picric acid [13]. The typical prior austenite grain structure was quantified at the quarter-thickness position by measuring the mean linear intercepts along the rolling (RD), normal (ND) and transverse directions (TD). Based on these measurements, the total reduction below the recrystallization temperature $\left(\mathrm{R}_{\mathrm{tot}}\right)$ were determined using the equation given in Ref. [14]. Supplementary microstructure characterizations were performed using the Oxford-HKL acquisition and analysis software following the microstructural classification described in Ref. [15]. For the EBSD measurements, the FESEM was operated at $10 \mathrm{kV}$ and the step size was $0.2 \mu \mathrm{m}$. Tensile tests were conducted in accord with the European standard EN 10002. Microhardness was measured using a Micro-Hardness Tester (CSM) under $1 \mathrm{~N}$ load with ten measurements at eight depths below the surface and the centerline.

\section{RESULTS AND DISCUSSION}

\subsection{Microstructure}

A summary of the austenite and effective grain size (d, EBSD high-angle boundaries $>15^{\circ}$ ) measurements is presented in Table II. An example of the influence of FRT on the austenite morphology at the quarterthickness of the strips in the high-Mn steel is depicted in Fig. 1, showing an increase in the total reduction below $\mathrm{T}_{\mathrm{NR}}\left(\mathrm{R}_{\mathrm{tot}}\right)$ with a decrease in FRT. The Low Mn-800 sample essentially showed the formation of mainly granular bainite, and hence, the measurement of prior austenite grain shape could not be performed for this sample. The chemical composition of the steels did not affect the total rolling reduction below the recrystallization temperature $\left(\mathrm{R}_{\mathrm{tot}}\right)$ when comparing the same finish rolling temperatures: $\mathrm{R}_{\text {tot }}$ was approx. 53-55\% with high FRT and approx. 66-68\% with low FRT for both steels. Similarly, the surface area of the austenite grain boundaries per unit volume $\left(\mathrm{S}_{\mathrm{V}}\right)$ increased and the effective grain size decreased while the prior austenite grain size decreased, indicating that the sizes of the grains are clearly refined by lowering FRT, as reported in previous studies [3]. 

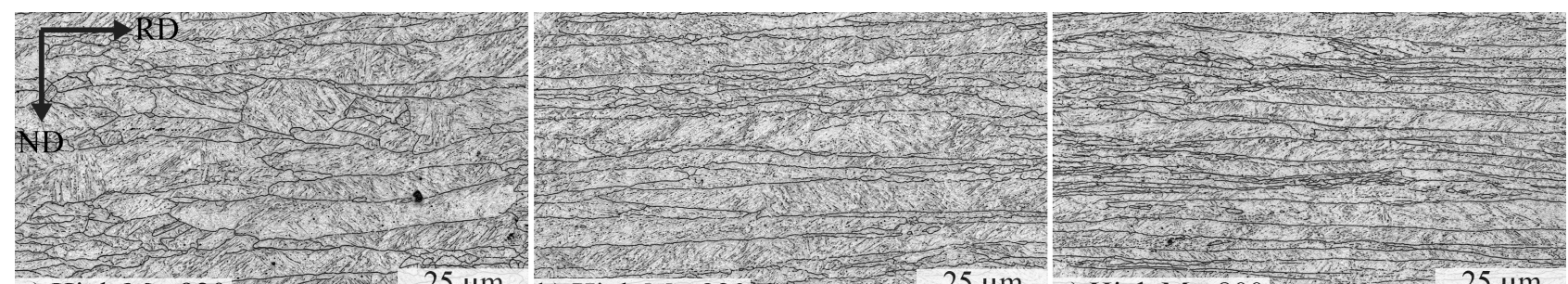

a) High Mn-920

$25 \mu \mathrm{m}$

b) High Mn- 880

$25 \mu \mathrm{m}$

c) High Mn-800

$25 \mu \mathrm{m}$

Fig. 1 LSCM images of prior austenite morphologies following etching with picric acid: High Mn steel with (a) 920, (b) 880 and (c) $800 \mathrm{FRT}$ at the quarter-thickness as seen in RD-ND sections.

Table II. Mean linear intercept measurements* of the prior austenite grain structure $(\mu \mathrm{m})$ along the three principal directions. Measurements of $R_{t o t}, S_{v}$, and d based on EBSD data including the 95\% confidence limits of the means are also given.

\begin{tabular}{lcccccc}
\hline Material & $\begin{array}{c}\bar{L}_{R D}, \\
\mu \mathrm{m}\end{array}$ & $\begin{array}{c}\bar{L}_{T D}, \\
\mu \mathrm{m}\end{array}$ & $\begin{array}{c}\bar{L}_{N D}, \\
\mu \mathrm{m}\end{array}$ & $\begin{array}{c}\mathrm{R}_{\text {tot, }}, \\
\%\end{array}$ & $\begin{array}{c}\mathrm{S}_{\mathrm{V}}, \\
\mathrm{mm}^{2} / \mathrm{mm}^{3}\end{array}$ & $\begin{array}{c}\mathrm{d}, \\
\mu \mathrm{m}\end{array}$ \\
\hline Low Mn-920 & $18.2 \pm 1.5$ & $12.8 \pm 0.9$ & $3.7 \pm 0.2$ & 55 & 335 & $1.29 \pm 0.03$ \\
Low Mn-880 & $23.1 \pm 2.1$ & $10.9 \pm 0.7$ & $3.3 \pm 0.1$ & 62 & 376 & $1.24 \pm 0.03$ \\
Low Mn-840 & $33.3 \pm 3.7$ & $14.5 \pm 1.1$ & $3.5 \pm 0.1$ & 67 & 335 & $1.49 \pm 0.05$ \\
Low Mn-820 & $25.5 \pm 2.5$ & $10.6 \pm 0.7$ & $3.0 \pm 0.1$ & 66 & 405 & $1.23 \pm 0.04$ \\
Low Mn-800 & \multicolumn{7}{c}{ Granular bainitic, hence cannot measure } & $1.56 \pm 0.07$ \\
High Mn-920 & $19.4 \pm 1.6$ & $11.0 \pm 0.7$ & $4.2 \pm 0.2$ & 53 & 310 & $1.53 \pm 0.06$ \\
High Mn-880 & $21.2 \pm 1.9$ & $10.3 \pm 0.6$ & $2.9 \pm 0.1$ & 63 & 423 & $1.21 \pm 0.03$ \\
High Mn-820 & $22.8 \pm 2.1$ & $9.4 \pm 0.7$ & $2.5 \pm 0.1$ & 67 & 482 & $1.09 \pm 0.03$ \\
High Mn-800 & $25.5 \pm 2.5$ & $10.2 \pm 0.6$ & $2.6 \pm 0.1$ & 68 & 461 & $1.07 \pm 0.02$ \\
\hline
\end{tabular}

*at the quarter-thickness of the strip

The microstructures at the centerline and subsurface of the specimens, as ascertained on the basis of FESEM observations, are listed in Table III. The transformation microstructures of the specimens consisted of mixtures of quasi- or polygonal ferrite (F), granular bainite (GB), upper bainite (UB) and auto-tempered martensite (ATM). In Table III, "main phase" means that the phase constituted more than $50 \%$ of the microstructure and "minor phase" less than 50\%. Microstructures at the centerline consisted of mostly autotempered martensite with some bainite. A decrease of FRT increased the fraction of softer microstructures like ferrite and granular bainite. As with the subsurface microstructures, a decrease of FRT increased the incidence of GB and $\mathrm{F}$ at the expense of ATM and UB.

Table III. Microstructural characterization of investigated materials at the centerline and between 50 and $400 \mu \mathrm{m}$ below the surface.

\begin{tabular}{|c|c|c|c|c|}
\hline \multirow[b]{2}{*}{ Material } & \multicolumn{2}{|r|}{ Centerline } & \multicolumn{2}{|c|}{ Subsurface } \\
\hline & Main phase & Secondary phase & Main phase & Secondary phase \\
\hline Low Mn-920 & ATM $80 \%$ & UB $20 \%$ & UB & GB, ATM \\
\hline Low Mn-880 & ATM $50 \%$ & UB $40 \%$, GB $10 \%$ & UB & $\mathrm{GB}, \mathrm{F}, \mathrm{ATM}$ \\
\hline Low Mn-840 & UB $50 \%$ & GB $40 \%$, ATM $10 \%$ & GB & F, UB \\
\hline Low Mn-820 & UB $45 \%$ & GB $40 \%$, F $10 \%$, ATM $5 \%$ & GB & $\mathrm{F}$ \\
\hline Low Mn-800 & GB $50 \%$ & UB $30 \%$, F $15 \%$, ATM $5 \%$ & GB & $\mathrm{F}$ \\
\hline High Mn-920 & ATM $100 \%$ & - & ATM & $\mathrm{UB}, \mathrm{GB}$ \\
\hline High Mn-880 & ATM $100 \%$ & - & UB & ATM, GB \\
\hline High Mn-820 & ATM $90 \%$ & UB $10 \%$ & UB & ATM, GB \\
\hline High Mn-800 & ATM $70 \%$ & UB $20 \%$, GB $10 \%$ & UB & ATM, GB \\
\hline
\end{tabular}

\subsection{Tensile properties and microhardness}

Tensile testing in the longitudinal direction showed reasonably high strength levels for the two steels, as showed in Fig. 2a. The yield strength and tensile strength of the studied steels vary in the ranges 790-1180 $\mathrm{MPa}$ and 930-1250 MPa, respectively, depending on the FRT. In general, the higher Mn version (1.8\% Mn) showed higher strength compared to that of the low-Mn steel $(1.4 \% \mathrm{Mn})$, irrespective of the FRT, obviously as a consequence of the differences in the transformed microstructures. 
The subsurface and centerline microhardness profiles presented in Figs. 2b-c show that the hardness throughout the thickness increases with increasing FRT. It can also be seen that the shapes of the hardness profiles are very similar. The polygonal ferrite in the surface layer (depth of $50 \mu \mathrm{m}$ ) is the softest phase, with a microhardness in the range 270 to $300 \mathrm{HV}$ (Fig. 2b). Furthermore, the difference in the hardness levels between the steels comprising different manganese content can be seen. In the high-Mn steel, the finish rolling temperature has no significant effect on the hardness profiles and the hardness is higher than in the low-Mn steel. Also, the hardness increases more rapidly with depth (at about $100 \mu \mathrm{m}$ ) from approx. 340$390 \mathrm{HV}$ to $430-470 \mathrm{HV}$ (Fig. 2c) corroborating the higher tensile strengths seen in these samples (Fig. 2a). The low-Mn steel samples comprised mainly auto-tempered martensite and upper bainite from $100 \mu \mathrm{m}$ below the surface to the centerline, thus corroborating lower strengths seen in these samples, as seen in Table III.
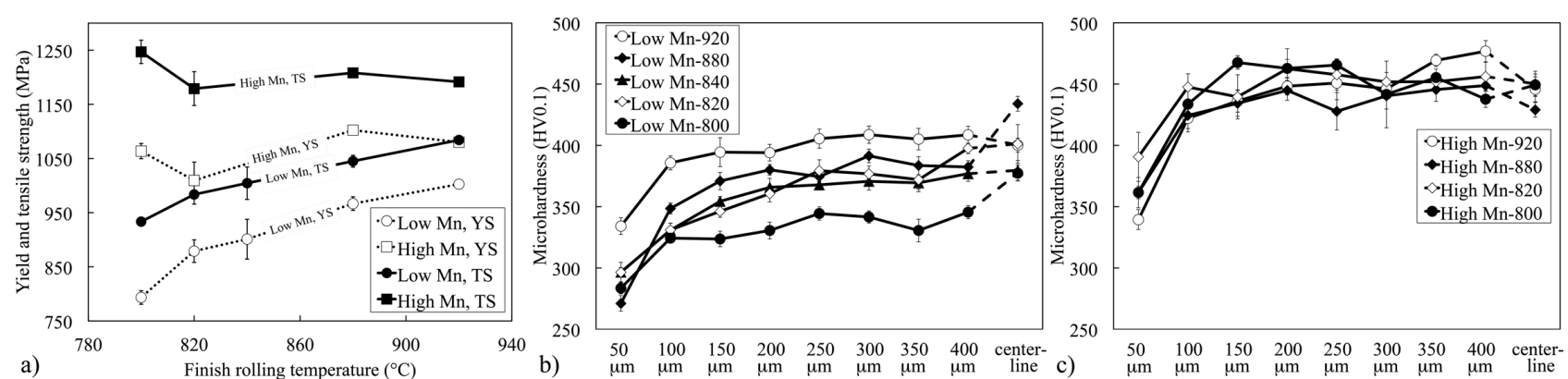

Finish rolling temperature $\left({ }^{\circ} \mathrm{C}\right)$
Fig. 2 Effect of FRT on mechanical properties (in the longitudinal direction): (a) yield stress (YS) and tensile strength (TS). Mean values of microhardness vs. depth below the surface for different FRT's in (b) Low Mn and (c) High Mn steel.

\subsection{JMatPro ${ }^{\circledR}$ simulations}

Fig. 3 shows JMatPro ${ }^{\circledR}$ predicted CCT diagrams for recrystallized austenite with the investigated compositions. The phase transformation start temperatures were quite similar for both steels at the high cooling rates, $20-100{ }^{\circ} \mathrm{C} / \mathrm{s}$, where $\mathrm{M}_{\mathrm{S}}$ temperatures are $439{ }^{\circ} \mathrm{C}$ and $419{ }^{\circ} \mathrm{C}$ in the low-Mn and high-Mn steels, respectively. However, with a further decrease in cooling rate, there is an appreciable difference in the phase transformation start temperatures, with the high-Mn steel showing lower transformation temperatures due to the presence of higher Mn (1.8\%) and slightly higher C $(0.08 \%)$ contents, Table I. As a consequence, simulated Vickers hardness data showed comparable hardness for high-Mn steel at all cooling rates. Furthermore, the bainite and ferrite curves were shifted to the right. Among those results, high-Mn steel provides mainly martensitic microstructure in the cooling rate range of interest for direct quenching of strips.

Although the CCT diagrams are not valid for deformed austenite, they do agree with the relative effects seen in the microstructures of the hot-rolled strips both at the core and the subsurface layers. The results are particularly interesting for the low-Mn steel, which showed lower yield and tensile strengths.
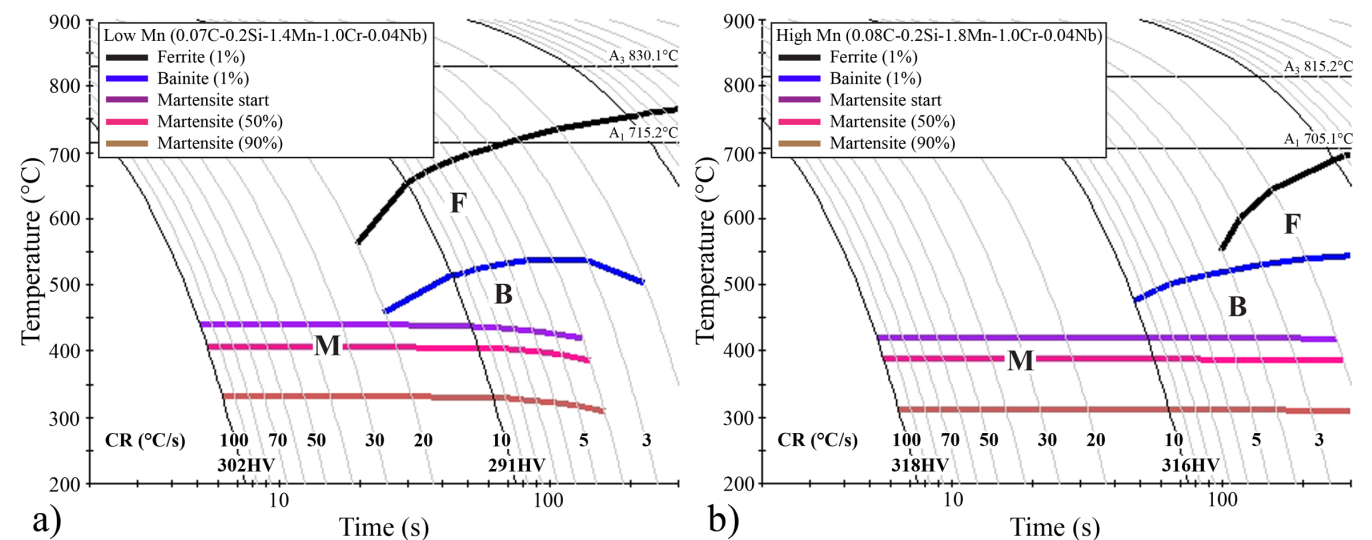

Fig. 3 Simulated CCT diagrams for a $20 \mu \mathrm{m}$ recrystallized austenite grain size and $950{ }^{\circ} \mathrm{C}$ austenitization temperature, plotted using JMatPro® software for (a) low-Mn and (b) high-Mn steel. (Abbreviations: $F=$ ferrite, $B=$ bainite and $M=$ martensite) 


\subsection{Relationships between chemical composition, microstructure and tensile properties}

Finish rolling temperature is important through its effect on the austenite grain structure, which strongly influences the mechanical properties of the final product. As can be observed from Fig. 1 and Table II, a higher FRT leads to less pancaking, higher effective grain size and hence to a coarser final microstructure, in contrast to the greater degree of pancaking observed at lower FRTs. Manganese has no effect on the predicted $\mathrm{T}_{\mathrm{NR}}$ temperature [12]; therefore the $\mathrm{T}_{\mathrm{NR}}$ temperature should be similar for the two steels, and thus explain the observed independence of the austenite pancaking level $\left(\mathrm{R}_{\mathrm{tot}}\right)$ on manganese content at a given FRT.

Despite the small differences in respect of carbon and manganese contents of the two steels, i.e., 0.4 wt.\% manganese and $0.01 \mathrm{wt} . \%$ carbon, the hardenability has increased appreciably, thus influencing the phase transformation kinetics and lowering the $\mathrm{B}_{\mathrm{S}}$ and $\mathrm{M}_{\mathrm{S}}$ temperatures marginally $[8,10]$. The effect of FRT on the phase fractions is illustrated in Fig. 4. The effect of low-temperature finish rolling, i.e., pancaking, depends on the hardenability of the steel. It is well established that diffusion-controlled transformations are strongly affected by austenite deformation, such that if the steel composition and/or cooling rate result in the formation of ferrite from recrystallized austenite, the phase transformation start temperature increases, i.e., the hardenability decreases, when the austenite is deformed [7].

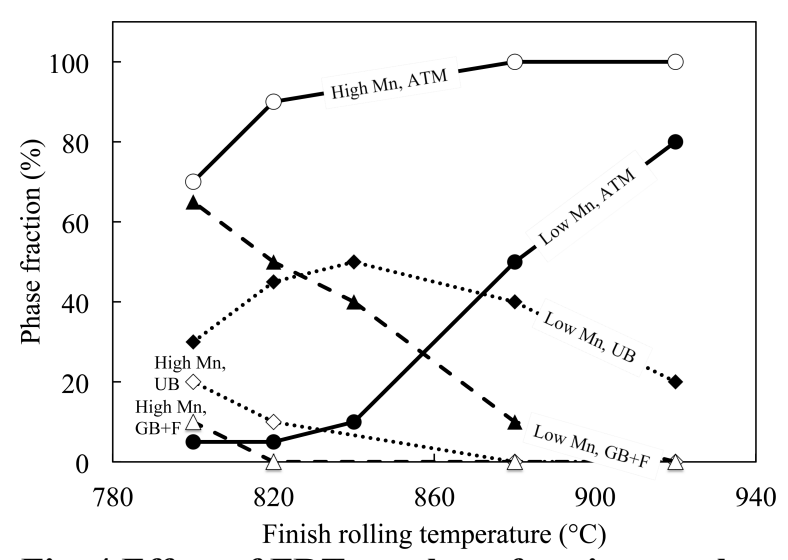

Fig. 4 Effect of FRT on phase fractions at the centerline.

During hot rolling, the steel temperature near the surface fluctuates strongly as the material flows into and out of the roll gap. Contact with the colder rolls rapidly chills the subsurface regions of the strip [16] as they enter the roll gap, while on leaving the roll gap, heat flow from deeper in the material rapidly reheats the subsurface layers. Thus, it is possible that in the case of low FRT, the surface temperature can drop momentarily to levels where the nucleation and limited growth of ferrite and/or granular bainite can occur even during hot rolling, whereas this would not occur for higher FRT. Such effects can be responsible for the complex nature of the microstructures nearest to the strip surface.

YS and TS initially increase with a decrease in FRT as a consequence of the increased pancaking and finer packets of martensite, but subsequently at lower FRTs, YS and TS decrease due to the formation of higher temperature transformation products.

Although, the bendability has not been reported in this study since the aim was to investigate hardenability, on the basis of the conclusions reported in Ref. [17], the present results suggest that bendability will be better in the case of the low-Mn steel due to its more beneficial subsurface hardness profile and microstructure. Similarly, a decrease in FRT should improve the bendability of both steels.

\section{CONCLUSIONS}

The purpose of this research was to investigate the effects of manganese content on the microstructure of hot-rolled and direct-quenched ultra-high-strength steels. The main observations and conclusions of the work can be summarized as follows: 
- Predicted CCT diagrams for undeformed, recrystallized austenite indicated that the compositional differences between the two studied steels should lead to significant differences in hardenability with the lower manganese and carbon contents promoting bainite and ferrite formation at the cooling rates of interest in direct quenching.

- An increase in the total reduction in the non-recrystallization temperature region $\left(\mathrm{R}_{\mathrm{tot}}\right)$ in conjunction with a lowering of the finishing rolling temperature (FRT) increased austenite pancaking.

- A decrease of FRT increased the formation of softer microstructures such as ferrite (F) and granular bainite (GB) in the subsurface layers. At high FRTs, the microstructures at the centerline consisted mainly of auto-tempered martensite (ATM), especially in the case of higher manganese content. Lowering FRT increased the fractions of GB and F at the expense of ATM and upper bainite (UB) in both the central and subsurface parts of the strip thickness.

- There was a tendency for the yield stress and tensile strength of the steel sheets to decrease on lowering FRT when F and GB formed.

\section{ACKNOWLEDGEMENTS}

This work was performed as a part of the Breakthrough Steels and Applications program of DIMECC Oy (the Digital, Internet, Materials \& Engineering Co-Creation), Finland. The financial support of the Finnish Funding Agency for Technology and Innovation (Tekes) is gratefully acknowledged.

\section{REFERENCES}

1. P. P. Suikkanen and J. I. Kömi, Mater. Sci. Forum 783-786, 246 (2014).

2. A. J. Kaijalainen, P. Suikkanen, L. P. Karjalainen, and J. J. Jonas, Metall. Mater. Trans. A 45, 1273 (2014).

3. A. J. Kaijalainen, P. P. Suikkanen, T. J. Limnell, L. P. Karjalainen, J. I. Kömi, and D. A. Porter, J. Alloys Compd. 577, S642 (2013).

4. H. Asahi, E. Tsuru, T. Hara, M. Sugiyama, Y. Terada, H. Shinada, S. Ohkita, H. Morimoto, N. Doi, M. Murata, H. Miyazaki, E. Yamashita, T. Yoshida, N. Ayukawa, H. Akasaki, M. L. Macia, C. W. Petersen, J. Y. Koo, N. V. Bangaru, and M. J. Luton, Int. J. Offshore Polar Eng. 14, 36 (2004).

5. M. Hemmilä, R. Laitinen, T. Liimatainen, and D. A. Porter, in Proc. 1st Int. Conf. "Super-High Strength Steels" (Associazone Italiana di Metallurgica - AIM, Rome, 2005).

6. A. J. Kaijalainen, P. P. Suikkanen, L. P. Karjalainen, and D. A. Porter, Mater. Sci. Eng. A 654, 151 (2016).

7. I. Kozasu, in Int. Conf. Thermomechanical Process. Steels Other Mater., edited by T. Chandra and T. Sakai (The Minerals, Metals \& Materials Society, Wollongong, 1997), pp. 47-55.

8. W. Steven and A. G. Haynes, J. Iron Steel Inst. 183, 349 (1956).

9. F. B. Pickering, in Microalloying '75, edited by M. Korchysky (Union Carbide Corporation, Washinghton DC, 1977), pp. 9-31.

10. Stuhlmann W., Härterei Tech. Mitteilungen 6, 31 (1954).

11. G. D. Wang, Z. D. Wang, J. B. Qu, Z. Y. Jiang, and X. H. Liu, in Int. Conf. Thermomechanical Process. Steels Other Mater., edited by T. Chandra and T. Sakai (The Minerals, Metals \& Materials Society, Wollongong, 1997), pp. 717-723.

12. F. Boratto, R. Barbosa, S. Yue, and J. J. Jonas, in THERMEC-88, edited by I. Tamura (Iron and Steel Institute of Japan, Tokyo, 1988), pp. 383-390.

13. A. Brownrigg, P. Curcio, and R. Boelen, Metallography 8, 529 (1975).

14. R. L. Higginson and C. M. Sellars, Worked Examples in Quantitative Metallography (Maney, London, 2003).

15. G. Krauss, Steels - Processing, Structure, and Performance, 2nd ed. (ASM International, Materials Park, 2015).

16. J. Pyykkönen, P. Suikkanen, M. C. Somani, and D. A. Porter, Matériaux Tech. 100, S1 (2012).

17. A. J. Kaijalainen, M. Liimatainen, V. Kesti, J. Heikkala, T. Liimatainen, and D. A. Porter, Metall. Mater. Trans. A 47, 4175 (2016). 